УДК 006.91

ВАК 05.11.15

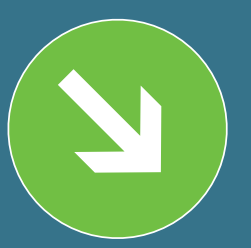

Ключевые слова:

диагностика по

фактическому

состоянию, вибро-

диагностика,

оценка точности и

согласованности

работы приводов,

планово-предупре-

дительный ремонт,

«Индустрия 4.0»

\title{
СОВРЕМЕННЫЕ МЕТОДЫ
} ДИАГНОСТИКИ СЛОЖНЫХ ТЕХНИЧЕСКИХ СИСТЕМ В УСЛОВИЯХ ЦИФРОВОГО
ПРОИЗВОДСТВА

\author{
Евгений ЮРЦЕВ, Юрий САВИНОВ, Дарья КУЛИКОВА, \\ Александра ЖИГАРЬ
}

\begin{abstract}
Рассмотрены методы диагностики оборудования по фактическому состоянию, такие как вибродиагностика, оценка точности и согласованности работы приводов. Представлены результаты расчетов эффективности применения данных методов.
\end{abstract}

Большинство отечественных предприятий в настоящее время осуществляет техническое обслуживание и ремонт оборудования по системе планово-предупредительного ремонта (ППР) [1]. Типовая система ППР базируется на том, что ремонт оборудования осуществляется с заданной периодичностью и в заданном объеме. Объем работ, периодичность их выполнения и трудоемкость, необходимое количество рабочих регламентируются в зависимости от типа оборудования.

Для проведения капитального ремонта станка необходимо провести его полную разборку. При этом множество деталей подвергается поломкам и не подлежат дальнейшему использованию [2]. Из этого вытекает, что применение данной системы технического обслуживания и ремонта влечет за собой значительные затраты труда рабочих, долгий простой оборудования, а также большие затраты на закупку комплектующих.

Для определения состояния подшипников следует их демонтировать. В подавляющем большинстве случаев демонтаж осуществляется ударным методом, что приводит к появлению дефектов как в самом подшипнике, так и в сопрягаемых деталях [3]. Не всегда необходимо проводить полный комплекс работ. Зачастую из строя выходят только один или несколько узлов станка. Однако, при ремонте по системе ППР, выводятся из строя в том числе и работоспособные узлы и детали, что приводит к ненужным потерям, как временным, так и финансовым.

В настоящее время растет номенклатура многофункциональных станков, станков нетрадиционной компоновки и станков с ЧПУ, что требует пересмотра существующей системы технического обслуживания и ремонта, поскольку данные виды оборудования сложны в ремонте, а сам ремонт требует больших затрат.

При переходе к концепции «Индустрия 4.0» определяющим направлением становится задача обеспечения безаварийной, предсказуемой работы технологического оборудования. Обслуживание станков на основе системы ППР, основанной на концепциях, разработанных в 70-80-х годах прошлого века, в основе которой лежит продолжительность работы оборудования, не обеспечивает на должном уровне ни безаварийной работы технологического оборудования, ни предсказуемости обеспечения точности и надежности станков. Необходим переход к поддержанию техники в работоспособном состоянии на основе идентификации ее технического состояния, включая детали и узлы станка, обеспечивающие точность изготовления, в том числе шпиндельные узлы, привода подач, поворотные столы, подшипники, шарико-винтовые пары, зубчатые и ременные передачи, электродвигатели, насосы. 


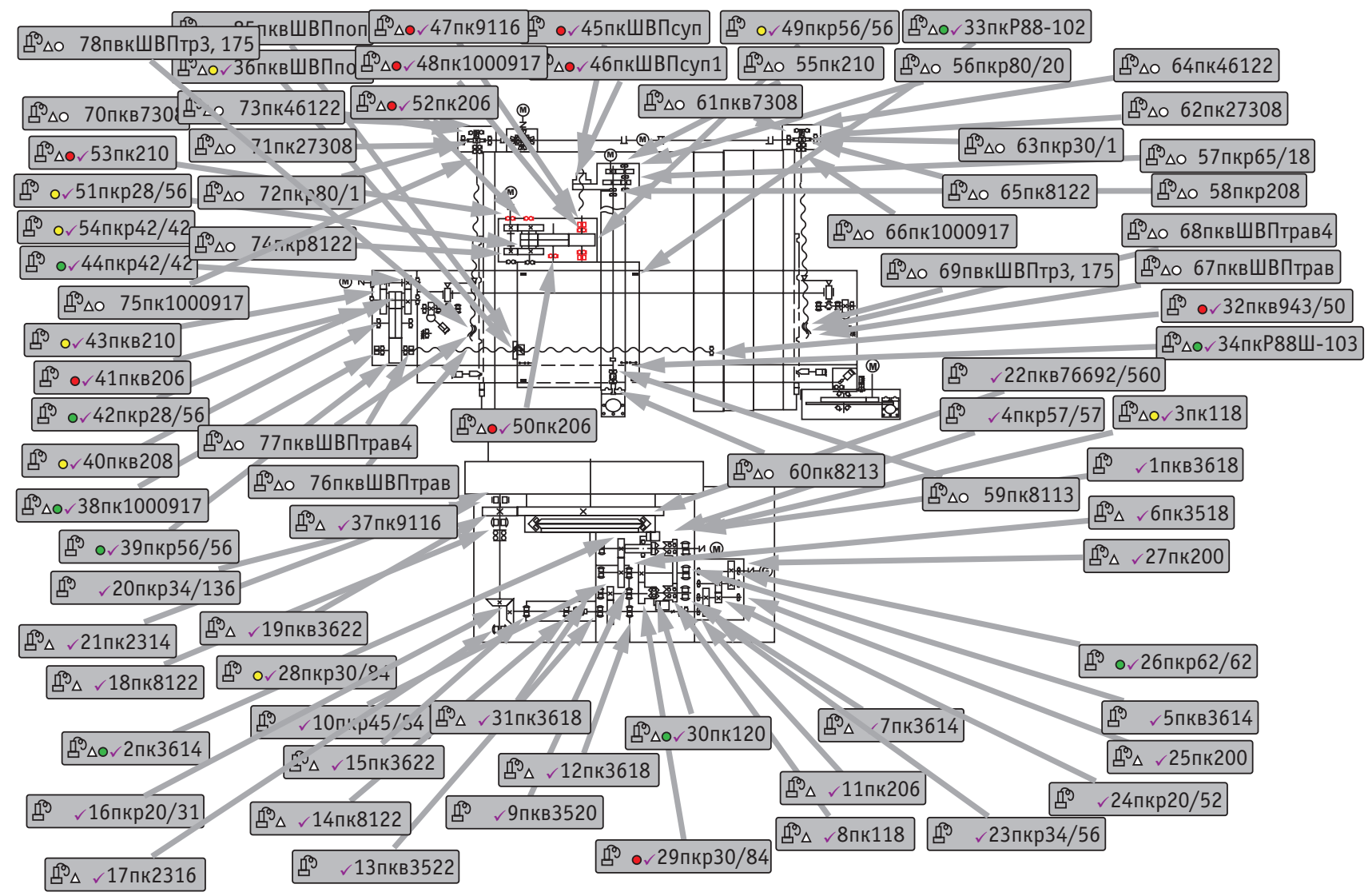

\section{Puc. 1. Математическая модель станка мод. 1М512МФ3}

На большинстве промышленных предприятий развитых стран используются современные методы обслуживания роторных систем по их фактическому состоянию на основе методов безразборной диагностики [4]. Они позволяют получить большее количество информации о состоянии станка, его узлов и деталей, а также значительно сэкономить трудовые и денежные ресурсы. К тому же диагностика является более информативной, так как проверяются не только показатели станка, но и качество сборки [3], наличие перекосов подшипников или шестерен, излишнее биение шпинделей, валов, правильность выставления винтов шарико-винтовых пар (ШВП) относительно направляющих и т.д.

Одной из самых информативных является методика вибродиагностики. Она позволяет получить вибрационные характеристики станка, которые непосредственно связаны с его параметрами и напрямую определяют различные показатели его точности.

В качестве примера рассмотрим результаты проведения вибродиагностики двух токарно-карусельных станков модели 1М512МФ3.

На рис. 1 изображена математическая модель рассматриваемого станка - его цифровой двойник. На ней отмечены все узлы и детали, определяющие выходные показатели станка. После проведения измерений и идентификации дефектов на цифровой модели отражается реальное состояние всех входящих элементов, красным цветом выделены те, у которых износ превышает установленные допустимые пределы, желтый цвет отражается на деталях, имеющих износ в допустимых пределах, зеленым цветом обозначены элементы, не имеющие износа. В том числе приводятся данные и по величинам износа.

Представление итоговых результатов проведенной вибродиагностики возможно в графическом виде, согласно схеме состояния деталей станка. Для токарно-карусельных станков модели 1М512МФ3 № 1 и № 2 они представлены на рис. 2 и 3 соответственно.

Как видно из схемы состояния деталей станка модели 1М512МФ3 № 1, имеется следующий износ, превышающий допустимые пределы:

$\rightarrow$ в поворотном столе износились подшипники 3614,3618 и 2316 ;

$\rightarrow$ в продольном приводе износился винт ШВП и шарики, подшипники 206 и 1000917, роликовые опоры P88-102;

$\rightarrow$ в вертикальном приводе износилась гайка и шарики ШВП, подшипники 9116 и 1000917. 


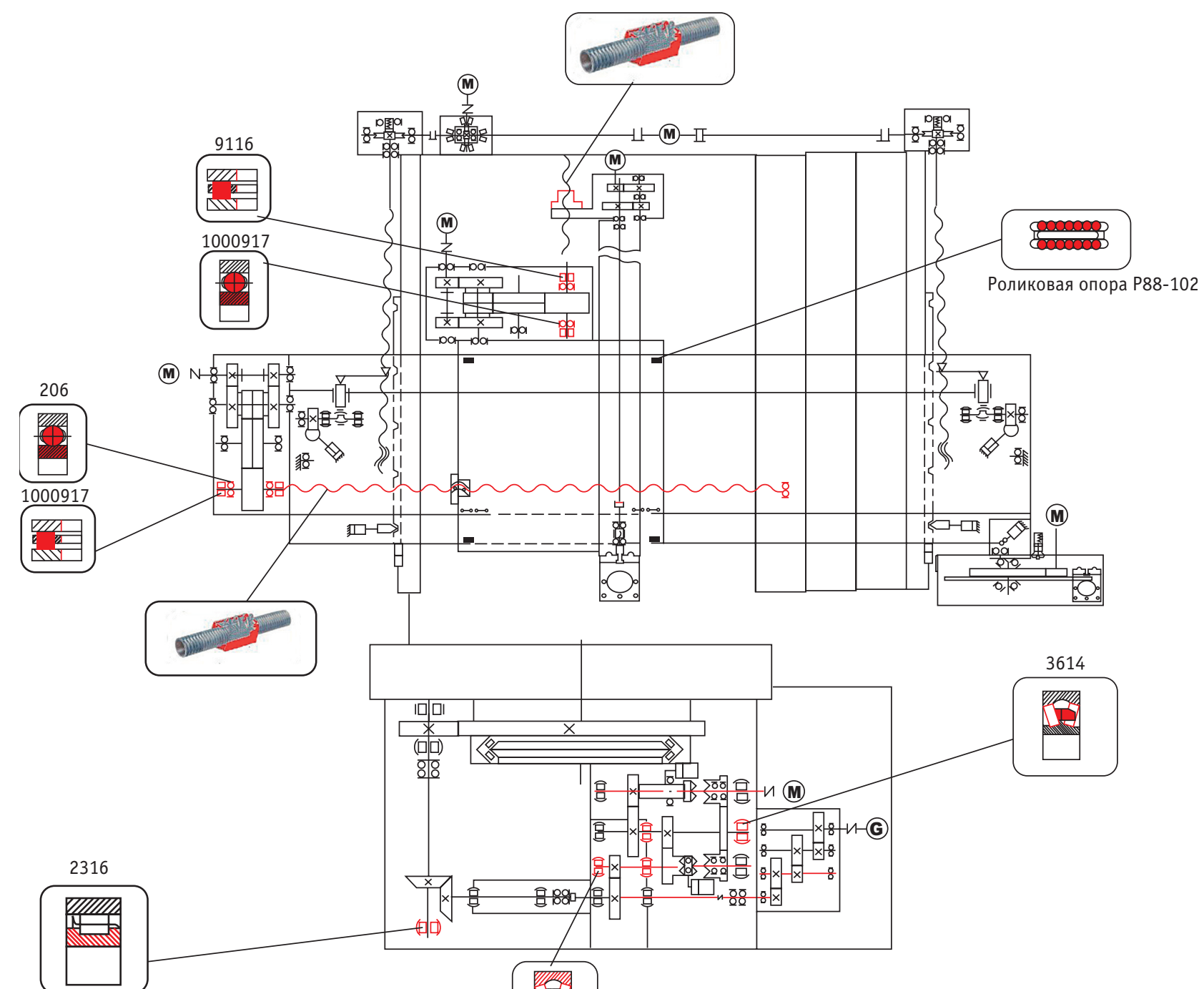

Puc. 2. Схема состояния деталей станка мод. 1М512МФ3 № 1

Из схемы состояния деталей станка модели 1М512МФ3 № 2 следует, что имеется следующий износ, превышающий допустимые пределы:

$\rightarrow$ в вертикальном приводе износились подшипники 9116 и 1000917, установленные на винте ШВП;

$\rightarrow$ имеется износ подшипников 206 в редукторе привода.

Проведем сравнительные расчеты стоимости выполнения ремонтов в соответствии с системой ППР и по фактическому состоянию.

Как следует из схем, ремонту подлежат лишь некоторые узлы станков. Соответственно, проведение ремонта по фактическому состоянию снижает затраты на закупку комплектующих на $14 \%$ для станка № 1 и на $90 \%$ для станка № 2, поскольку замене будут подлежать не все детали, входящие в состав узлов станка, а только детали, входящие в узлы, подлежащие ремонту.

Согласно системе ППР, трудоемкость капитального ремонта определяется через единицу ремон- тосложности. Регламент устанавливается в зависимости от типа станка.

Проведение ремонта по фактическому состоянию на основе вибродиагностики позволяет сократить трудоемкость капитального ремонта.

В частности, на $60 \%$ для станка № 1 и на $80 \%$ для станка № 2 сократится время, затрачиваемое на механическую обработку деталей узлов (на изготовление или восстановление деталей). На $42 \%$ для станка № 1 и на $64 \%$ для станка № 2 сократится время слесарных работ (разборка и сборка станка). Суммарное время капитального ремонта сократится на 39 и $58 \%$ для станков № 1 и № 2 соответственно.

Сокращение трудоемкости также вытекает из того, что проведение ремонта по фактическому состоянию исключает заведомо ненужные работы, такие как разбор узлов станка, не вышедших из строя и имеющих ресурс для дальнейшего функционирования. 


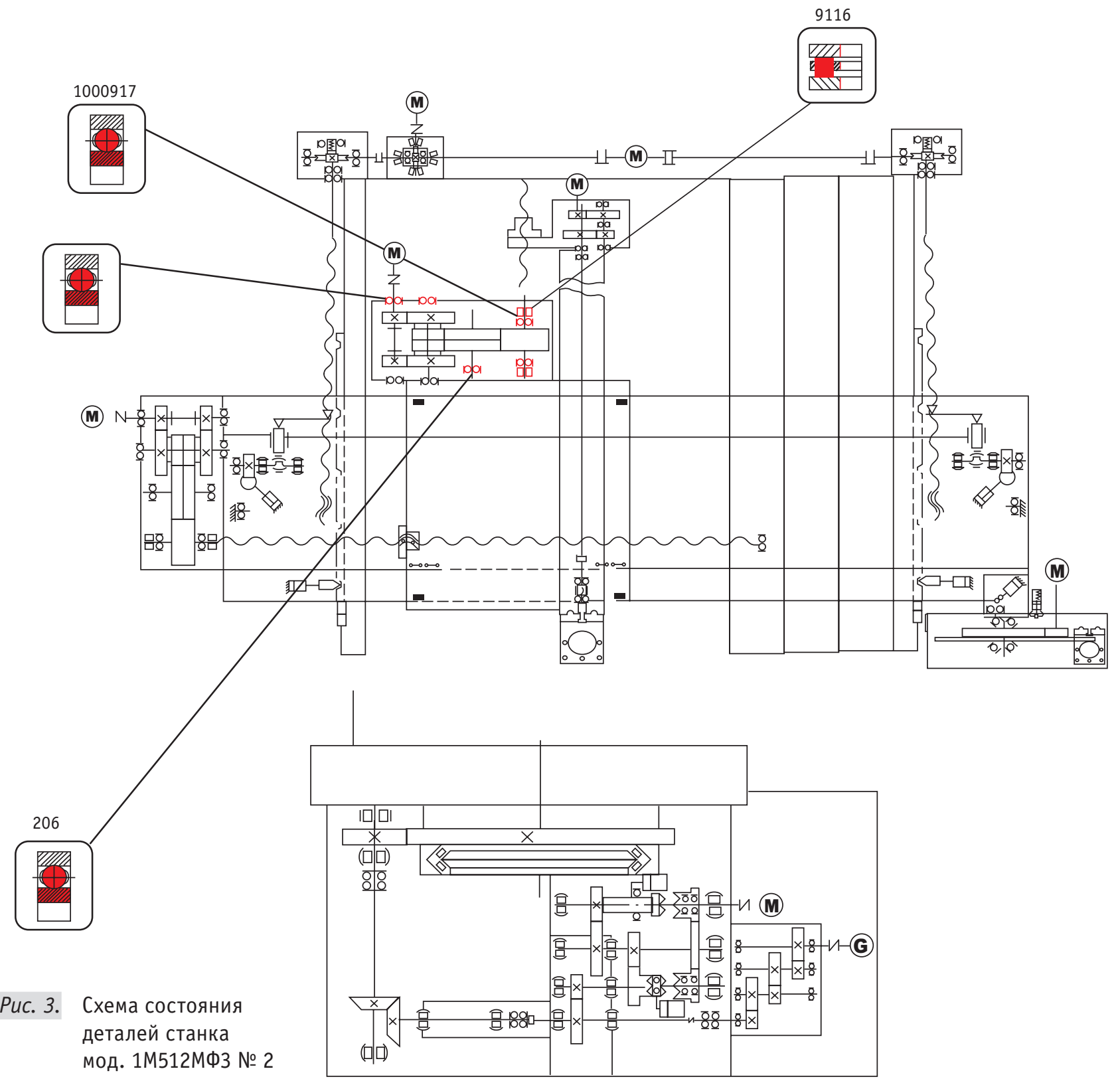

Само сокращение трудоемкости капитального ремонта приводит к двум важным результатам: сокращению затрат на заработную плату рабочих, осуществляющих ремонт, а также уменьшению времени простоя оборудования, что позволяет увеличить его производительность.

Таким образом, для станков модели 1М512МФ3, подошедших согласно графику выполнения планово-предупредительного ремонта к проведению капитального ремонта, с полной разборкой, в реальности необходимо выполнить только ограниченный объем работ.

При применении метода ремонта оборудования по фактическому состоянию вместо полной разборки станков требуется разбор лишь тех узлов, где имеются дефектные детали. Сокращается время ремонта, уменьшаются затраты на закупку комплектующих. Следовательно, переход на систему ремонта оборудования по фактическому состоянию, в частности применение методики вибродиагностики станков, позволяет получить существенный экономический эффект.

Важнейшей составляющей обеспечения точности станков при эксплуатации является своевременная регулировка параметров, обеспечивающих заданную точность. При проведении работ на обрабатывающих центрах появляются значительные погрешности, связанные с динамическими ошибками. К ним относятся, например, выбросы обратного хода или перерегулировка приводов. Данные ошибки вызваны тем, что при смене направления движения приводов станка 


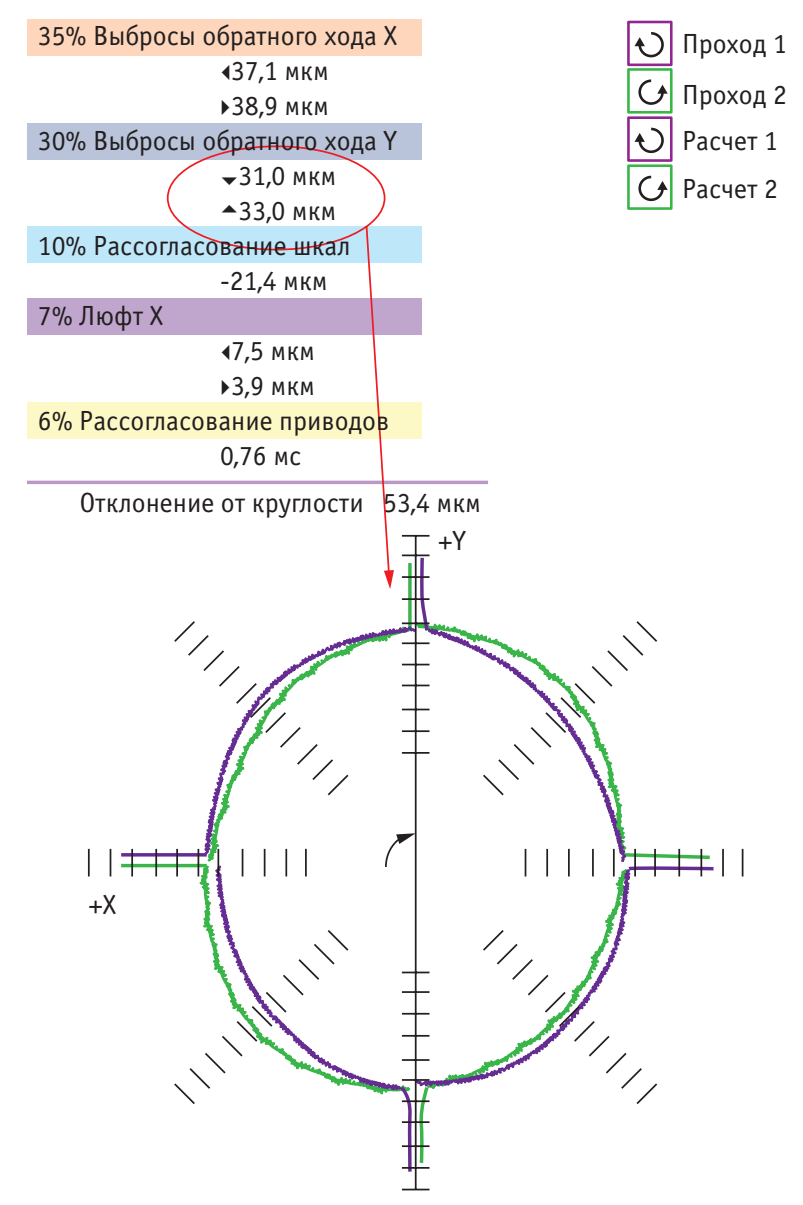

Puc. 4. Результаты проверки точности и согласованности работы приводов станка МАНО 1000С в плоскости $X$ и $Y$

наблюдаются пиковые значения перемещений, приводящие к появлению подрезов на детали при фрезеровании с круговой интерполяцией. Величина подрезов определяется величинами обратного хода и диаметром расточки.

В современной производственной практике метод оценки точности и согласованности работы приводов станка используется на станках с ЧПУ при одновременной работе двух приводов, то есть при наиболее сложном кинематическом режиме работы станка [5]. В качестве оборудования, необходимого для диагностики, использовалась аппаpaтypa Renishaw Ballbar QC-20W. Данный прибор позволяет определить как наличие продольных и боковых люфтов, так и их численные значения в микрометрах, степень рассогласованности приводов, отклонений от прямолинейности и перпендикулярности, выбросы обратного хода, циклические ошибки и др. Диагностика производится при помощи электронно-механического прибора с разрешением 0,1 мкм и программы расшифровки полученных данных. Согласно методике, при-

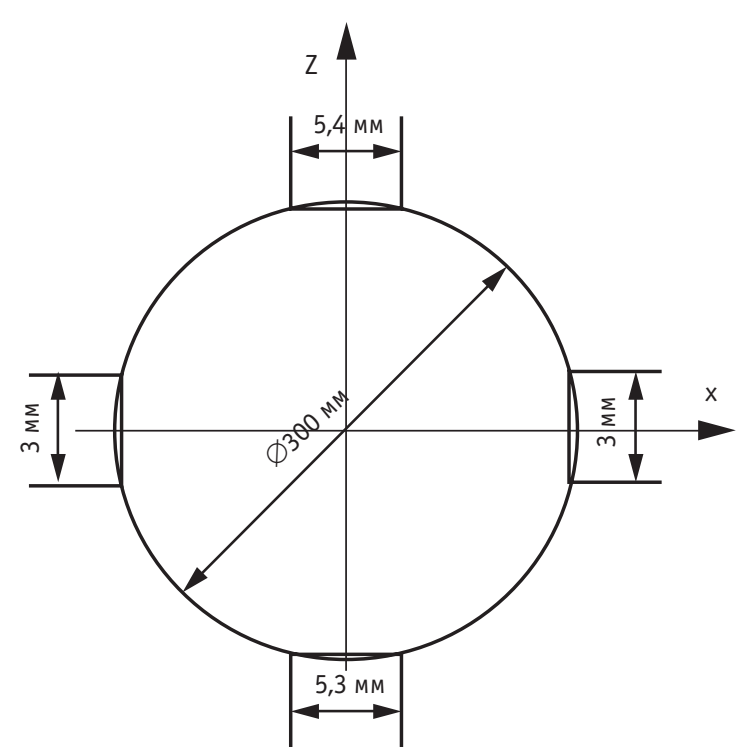

Puc. 5. Величины подрезов при фрезеровании по окружности на станке МАНО 1000С при диаметре обработки 300 мм и подаче 500 мм/мин

веденной в стандартах ISO 230-4 и ГОСТ 30544-97 [6], сначала выполняются два прохода по воспроизведению круговой траектории против часовой стрелки, а затем два прохода по часовой стрелке. В процессе испытания контроль круговой траектории, движение по которой выполняется согласованными действиями приводов станка, проводится с использованием высокоточных измерительных средств.

С помощью метода оценки точности и согласованности приводов определяются 17 важнейших параметров рабочего состояния станка [7], основными из которых являются:

$\rightarrow$ люфты по каждой координате;

$\rightarrow$ боковые люфты;

$\rightarrow$ рассогласование скорости приводов;

$\rightarrow$ неперпендикулярность осей;

$\rightarrow$ непараллельность по каждой оси.

В результате проведения диагностики:

1. формируется отчет, включающий графики и таблицы расшифровки неисправностей;

2. проводится анализ данных, содержащихся в графиках и таблицах;

3. разрабатываются рекомендации по устранению неисправностей.

Метод оценки точности и согласованности приводов был применен на обрабатывающем центре модели МАНО 1000С, оснащенном поворотной фрезерной головой для вертикальной и горизонтальной обработки деталей, шпинделем с максимальной частотой вращения до 2000 об/мин. В итоге были получены результаты, представленные на рис. 4. 


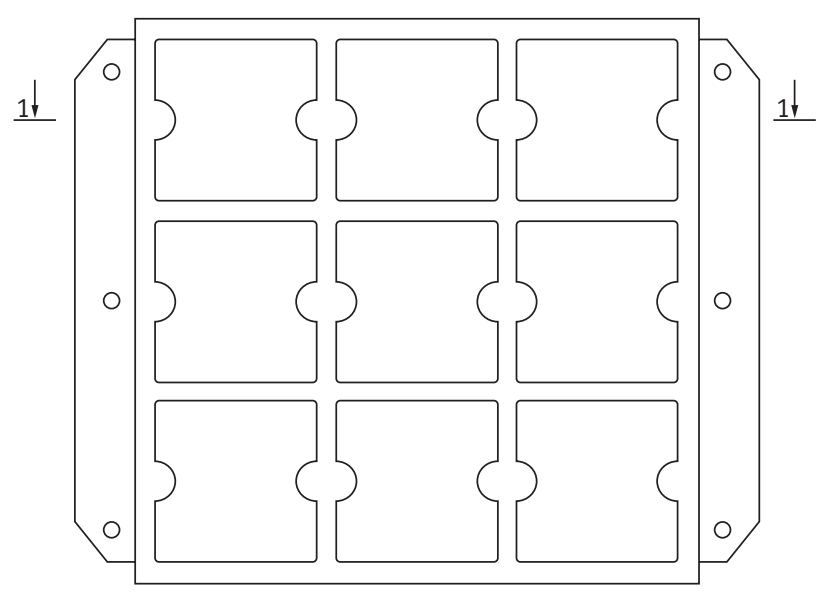

$1-1$

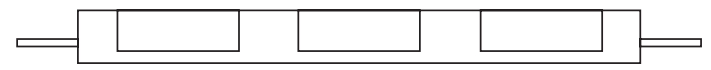

Puc. 6. Обрабатываемая деталь

На основании измерений рассчитаны величины возникающих подрезов в зависимости от диаметра расточки и величин рабочих подач.

Расчет показывает, что при диаметре обработки 300 мм и подаче 500 мм/мин подрезы в плоскости $X$ и $Y$ будут иметь величины 3 и 5,4 мм (рис. 5).

Такие величины подрезов при фрезеровании недопустимы, поэтому у оператора станка остается единственная возможность избежать их появления - это снижение скорости подачи, которую он устанавливает при фрезеровании по окружности в пределах 15-20 мм/мин, при рекомендуемых 500 мм/мин. В результате снижения скорости значительно теряется производительность.

Произведем анализ эффективности диагностики при помощи метода оценки точности и согласованности приводов на примере обработки детали на станке МАНО 1000С. Для этого определим эффект, полученный от использования метода при сопоставлении производительности на различных режимах работы станка. Деталь, используемая в примере, изображена на рис. 6.

При обработке детали без применения метода оценки точности и согласованности приводов оператор станка устанавливает скорость подачи на уровне 20 мм/мин.

Время обработки одной детали (штучное время) складывается из трех элементов:

$\rightarrow$ оперативное время - продолжительность выполнения технологической операции;

$\rightarrow$ время обслуживания рабочего места;

$\rightarrow$ время на личные надобности и отдых.

Оперативное время подразделяется на основное время, в течение которого происходит изменение формы и размеров детали, и вспомогатель- ное время, включающее в себя установку и снятие детали.

Время обслуживания рабочего места состоит из технического и организационного времени.

Для определения штучного времени обработки одной детали $\left(t_{\amalg}\right)$ воспользуемся формулой:

$$
t_{\mathrm{\amalg}}=t_{\mathrm{o}} \cdot(1+\delta) \cdot\left(1+\frac{(\alpha+\beta+\gamma)}{(100 \%)}\right),
$$

где $t_{0}$ - оперативное время, то есть время работы станка по программе управления, мин; $\delta$ - соотношение вспомогательного и основного времени; $\alpha-$ процент времени технического обслуживания рабочего места от оперативного времени, $\% ; \beta$ - процент времени организационного обслуживания рабочего места от оперативного времени, \%; $\gamma$ - процент времени на личные надобности и отдых от оперативного времени, \%.

Основное время для фрезеровочного станка с ЧПУ рассчитывается по формуле:

$$
t_{\mathrm{0}}=\frac{L}{S_{\Pi}},
$$

где $L$ - расчетная длина обработки, мм; $S_{\text {п }}$ - скорость подачи, мм/мин.

Расчетная длина обработки для детали составляет 5400 мм. Следовательно, основное время выполнения детали № 1 на станке МАНО 1000С при скорости подаче 500 мм/мин будет равно:

$$
t_{02}=\frac{5400}{500}=10,8 \text { мин. }
$$

Среднестатистические величины соотношений вспомогательного времени, времени на техническое и организационное обслуживание рабочего места и времени на личные надобности и отдых с оперативным временем приведены в «Справочнике технолога-машиностроителя» [8] и составляют:

$\rightarrow$ соотношение вспомогательного и основного времени $\delta=0,085 t_{0}$;

$\rightarrow$ время технического и организационного обслуживания рабочего места $(\alpha+\beta)$ составляет $10 \%$ от $t_{0}$;

$\rightarrow$ время на личные надобности и отдых $\gamma$ составляет $4,5 \%$ от $t_{0}$.

Таким образом, при заданной скорости 500 мм/мин штучное время обработки детали будет равно:

$$
t_{\text {ш } 2}=10,8 \cdot(1+0,085) \cdot\left(1+\frac{10+4,5}{100}\right)=13,4 \text { мин. }
$$

При соблюдении рекомендации производителя по скорости обработки изготавливаемых деталей время обработки детали составляет 13,4 мин. Но, как отмечено выше, оператор станка вынужден снижать скорость из-за образования подрезов 
до 20 мм/мин. При таком режиме работы основное время выполнения детали на станке МАНО 1000С будет равно:

$$
t_{01}=\frac{5400}{20}=270 \text { мин. }
$$

При заданной скорости 20 мм/мин штучное время обработки детали будет складываться из основного и вспомогательного, рассчитанного путем уменьшения штучного времени изготовления детали при скорости подачи 500 мм/мин на величину основного времени в этом же режиме:

$$
t_{\text {ш } 1}=270+13,4-10,8=272,6 \text { мин. }
$$

То есть при снижении скорости резания в 25 раз (с 500 до 20 мм/мин) штучное время обработки детали увеличивается примерно в 20 раз (с 13,4 до 272,6 мин).

Если пренебречь подготовительно-заключительным временем, то количество произведенных деталей за смену $\left(n_{\mathrm{cm}}\right)$ рассчитывается по формуле:

$$
n_{\mathrm{cM}}=\frac{T_{\mathrm{cM}}}{t_{\mathrm{E}}},
$$

где $T_{\text {см }}$ - продолжительность смены, мин.

При скорости подачи 500 мм/мин за 8-часовую смену (480 мин) будет произведено:

$$
n_{\text {см } 2}=\frac{480}{13,4}=35,8 \rightarrow 35 \text { штук в смену. }
$$

При скорости подачи 20 мм/мин за 8-часовую смену (480 мин) за смену будет произведено:

$$
n_{\text {см } 1}=\frac{480}{272,6}=1,76 \rightarrow 1 \text { штука в смену. }
$$

Таким образом, производительность различается в 35 раз $\left(\frac{n_{\mathrm{cM} 2}}{n_{\mathrm{cM} 1}}=\frac{35}{1}=35\right)$, то есть эффект, полученный при регулировке станка при использовании метода оценки точности и согласованности приводов, очевиден при сопоставлении производительности при различных режимах работы станка. Следовательно, обслуживание станочного парка на основе эффективных методов диагностики приводит к значительному повышению производительности работы технологического оборудования.

\section{ВЫВоды}

Применение методов, основанных на оценке фактического состояния оборудования, позволяет получить существенный положительный эффект например, повышение производительности при использовании метода оценки точности и согласованности работы приводов или сокращение затрат при использовании метода вибродиагностики. Кроме того, переход на обслуживание станков по фактическому состоянию является одним из важных шагов при переходе к концепции «Индустрия 4.0», поскольку обеспечивает бесперебойное функционирование оборудования, а следовательно и всей производственной системы.

\section{ЛИТЕРАТУРА}

1. Клягин В.И., Сабиров Ф.С. Типовая система технического обслуживания и ремонта металлорежущего и деревообрабатывающего оборудования. М.: Машиностроение, 1988.

2. Савинов Ю.И., Перебасова В.М. Управление жизненным циклом оборудования на примере определения технического состояния станка DMU 100 Monoblock // СТАНКОИНСТРУМЕНТ. 2019. № 1. C. 104-109.

3. Савинов Ю.И. Определение параметров механических систем станков // Станки и инструмент. 2010. № 10. С. 8-10.

4. Барков А.В., Баркова Н.А., Азовцев А.Ю. Мониторинг и диагностика роторных машин по вибрации. - СПб: Изд. Центр СПбГМТУ, 2000. 159 c.

5. Савинов Ю.И. Полная диагностика горизонтально-расточного станка модели 2В622Ф4 // Главный механик. 2010. № 2. С. 48-55.

6. ГОСТ 30544-97. Станки металлорежущие. Методы проверки точности и постоянства отработки круговой траектории. - ГОССТАНДАРТ, 2001.

7. Савинов Ю.И. Повышение точности станков с ЧПУ при использовании методов безразборной диагностики // Ремонт, восстановление, модернизация. 2009. № 3. С. 11-15.

8. Справочник технолога-машиностростроителя / Под ред. А.Г. Косиловой и Р.К. Мещерякова. В 2-х т. Т. 1. - М.: Машиностроение, 1986. 656 с.

\section{ЮРЦЕВ Евгений Сергеевич -}

директор Центра технологического развития РКП ФГУП «НПО «Техномаш»

\section{САВИНОВ Юрий Иванович -}

кандидат технических наук, начальник отдела ФГУП «НПО «Техномаш»

\section{КУликовА Дарья Валерьевна -}

студентка МГтУ им. Н. Э. Баумана, практикантка ФГУП «НПО «Техномаш»

ЖиГАРЬ Александра Николаевна -

студенткка МГтУ им. Н. Э. Баумана, практикантка ФГУП «НПО «Техномаш» 


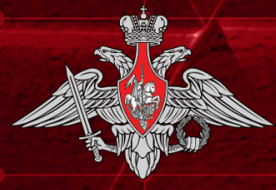

МИНИСТЕРСТВО ОБОРОНЫ РОССИЙСКОЙ ФЕДЕРАЦИИ
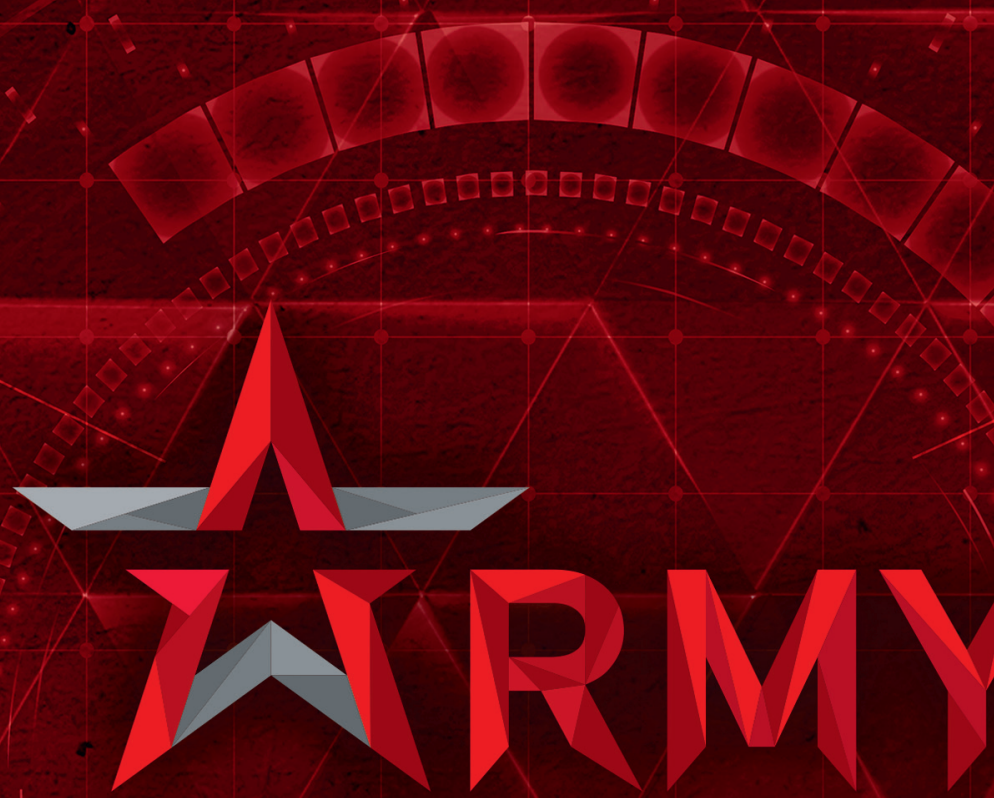

\section{МЕЖДУНАРОДНЫЙ ВОЕННО-ТЕХНИЧЕСКИЙ ФОРУМ «АРМИЯ-2020»}

\section{3-29 АВГУСТА ПАТРИОТ ЭКСПО}

WWW.RUSARMYEXPO.RU

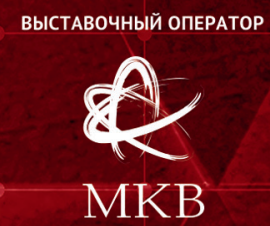

МЕЖДУНАРОДНЫЕ КОНГРЕССЫ И ВЫСТАВКИ

ГЕНЕРАЛЬНЫЙ БАНК ПАРTHEP

1 П псБ
ГЕНЕРАЛЬНЫЙ СПОНСОР

눈
ГЕНЕРАЛЬНЫЙ ФИНАНСОВЫЙ ПАРТНЕР 䓶 НОВИКОМБАНК
ГЕНЕРАЛЬНЫЙ ПАРТНЕР

๑ вертолеты России
ГЕНЕРАЛЬНЫЙ ПАРТНЕР АВИАКЛАСТЕРА

OAK
ОФИЦИАЛЬНЫЙ ПАРТНЕР

要此 